\title{
LEGIBILITY
}

$\leftarrow$

A major purpose of the Technical Information Center is to provide the broadest dissemination possible of information contained in DOE's Research and Development Reports to business, industry, the academic community, and federal, state and local governments.

Although a small portion of this report is not reproducible, it is being made available to expedite the availability of information on the research discussed herein. 


$$
" 1: i n
$$

\section{DE9 0011970}

TITLE Characterization of a Hirh-Tntensity, Subptcosecond Xecl Laser System

$\begin{array}{ll}\text { AUthoR(S): } & \text { Aniolnette J. 'I'aylor } \\ & \text { T'Lmothy R. Gosnell } \\ & \text { Jeff P. Roberts } \\ & \text { Dave C. MacPherson } \\ \text { Charles R. T'Rllman }\end{array}$

SUBmitred ro. Ultrafast. Phenomenn 'so

Monterey, CA

Mny $14-17,1990$

\section{DISCLAIMER}

This report was prepared as an account of work sponwored by an agency of the United Situtea Government. Neither the United States (iovernment nur any agency thereur, nor any of their employeen, makes any warranty, express or implied, or assumes any iegal liability or responajbility for the accuracy, completeness, or unefulnes of any information, upparalun. product, or process dimelomed, or represents that its use would not infringe privately owned rights. Reference here In to any specific commercial produc!, process, of service hy trade nume. trademark. munufacturer, or otherwise does not necessurily constitute of imply its endorsement, recommendation. or Favoring by the I/nited Stules ciovernment of any agency thereof The views and opinuons of wuthors expressed herein do not necessurily situte or reflect thase of the linied Siates liovernment or any agency therenf.

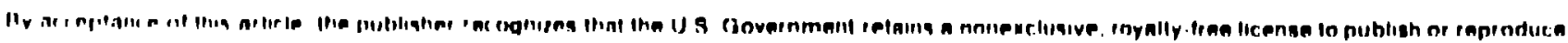

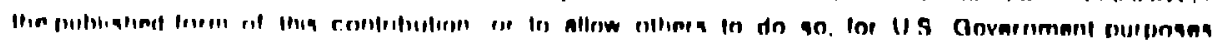


Characterization of a High-Intensity, Subpicosecond $\mathrm{XeCl}$ Laser System

A. J. 'íaylor, T. R. Gosnell, J. P. Roberts,

D. C. MacPherson and C. R. Tallman

Los Alamos National Laboratory

Los Alamos, NM 87545

Recent advances in ultrafast lasers and large-aperture optical amplifiers have spurred the development of terawatt-class laser systems capable of delivering focal-spot intensities in excess of $10^{19}$ $\mathrm{W} / \mathrm{cm}^{2}$. At these extremely high intensities, the optical field strength is more than twenty times larger than the Bohr electric field, e/ $\mathrm{a}_{\mathrm{o}}{ }^{2}$, permitting for the first time investigations of the optical properties of matter in a previously unexplored intensity regime.

We describe a terawatt-class laser system based on the amplification of subpicosecond pulses in $\mathrm{XeCl}$ discharge amplifiers. Although several terawatt laser systems have been previously reported:1-6 complete characterization of the performance of these devices has not been made: Only for a few of these systems has the final outpur pulsewidth been determined, while measurements of the focal-spot diameter obtained upon focusing of the fully amplified beam have not been reported at all. Nevertheless, a firm knowledge of these parameters, especially the focal-spot diameter, is absolutely essential for the meaningful interpretation of experimentil results. 
Given the extreme performance demanded of these systems, temporal and spatial distortion of the optical pulse during the amplification process should be the rule rather than the exception, making only indirect determinations of the final pulsewidth and beam quality unreliable. For these reasons, we have made a direct measurement of the output beam quality and carried out extensive measurements of the pulsewidth throughout the entire optical train.

The laser system is sketched in Figure 1, with pulsewidths and energy levels given for each stage. It consists of a front-end which generates $308-\mathrm{nm}$ seed pulses by frequency-doubling the output of a synchronously-pumped subpicosecond dye oscillator-amplifier system|71, followed by an amplifier chain comprised of a smallaperture $\left(1-\mathrm{cm}^{2}\right) \mathrm{XeCl}$ preamplifier, a beam-expanding vacuum spatial filter, and a large-aperture $\left(100-\mathrm{cm}^{2}\right)$ final amplifier[8]. The final amplifier consists of two independently pumped 2.5 -m-long discharge gain regions which share a common 130-keV, 10$\mathrm{mrad} / \mathrm{shot} \mathrm{x}$-ray preionizer. With $10-\mathrm{kV} / \mathrm{cm}, 100 \mathrm{~kW} / \mathrm{cm}^{3} \mathrm{discharge}$ and a gas mixture consisting of 2290-Torr Ne, 14-Torr Xt and 1-Torr $\mathrm{HCl}$, the centerline small-signal gain is $0.036 \mathrm{c}-1$ and useful gain is obtained over $60 \%$ of the aperture. In order to maintain neardiffraction-limited beam quality at a $1-H z$ repetition rate, a gas flow system is employed which maintains nearly laminar flow transverse to the discharge electrodes. After hot gas is cleared from the discharge volume, this flow system establishes less than $\lambda / 20$ wavefront distortion over $80 \%$ of the clear aperture hefore the alext shot is fired. 
Our $\mathrm{XeCl}$ laser system generates 250-mJ, 275-fs pulses at 308 $\mathrm{nm}$ and operates at a sustained repetition rate of $1 \mathrm{~Hz}$. The ultrashort output pulse lies on a 26 -ns, $50-\mathrm{mJ}$ ASE pedestal, but only half of the ASE is included in the solid angle subtended by the output beam. Using f/3.7 optics we measure FWHM focal-spot dimensions of $3.4 \mathrm{x}$ $4.1 \mu \mathrm{m}^{2}$ for the full-energy final output beam and therefore

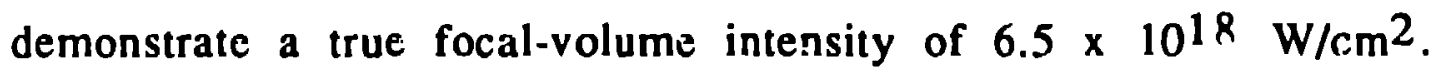
Since almost a factor of two temporal broadening occurs from the 150-fsec dye-oscillator pulse to the 275-fsec amplified output pulse, the evolution of the pulse duration and its spectral content are investigated. Autocorrelations of the pulse and its corresponding spectrum as it traverses the amplifier chain are presented in Figures 2 and 3. The autocorrelations, obtained using two-photon ionization of DABCO vapor, all exhibit the 3:1 contrast ratio indicative of wellmode-locked pulses.

The 190-fsec seed pulse with its relatively smooth $0.96-\mathrm{nm}$ wide frequency spectrum ( $2 a$ and $3 a$ ) broadens temporally to 270 fsec (2b) after amplification in the relatively low gain $(g \circ:=9)$ preamplifier. This type of broadening has been obscrved previnusly in $\mathrm{XeCl}|9|$ and is caused by modulation of the pulse's spectum by the $\mathrm{XeCl}$ gain profile (3b). After troversing the spatial filter, this pulse is broadened to $310 \mathrm{fsec}(2 \mathrm{c})$. An experimental investigation of this broadening reveals that it is caused not by the aperture in the spatial filter but by dispersion in the spatial filter optics: fused silica lenses $(0.5 \mathrm{~cm})$ and $\mathrm{Cal}_{2}$ windows $(2 \mathrm{~cm})$. The calculated broadening of at 27()-fsec, (0.89-nm, linearly chirped pulse after traversing this dispersive material is about $15 \%$, in agreement with llac 
experimental results. The effects of the final amplifier are twofold: With the amplifier turned off and evacuated, the pulse broadens from 310 to $375 \mathrm{fsec}$ (2d), as a result of group velocity dispersion in the amplifier's four $0.95-\mathrm{cm}$ quartz windows. This result is in reasonable agreement with the calculated broadening of $30 \%$ assuming a linearly-chirped $310-\mathrm{fs}, 0.89-\mathrm{nm}$ input pulse. On the other hand gain saturation during the amplification process in the final amplifier broadens the pulse spectrum (3c) and compresses the pulse to a final width of 275 fs (2e).

The large amount of dispersive material in the system, as well as the time-bandwidth product of the output pulse of 0.83 , i..dicate that pulse compression using passive components with net negative group velocity dispersion may yield a significantly shorter output pulse. We have used two prism pairs between the spatial filter and the final amplifier to provide ngative group velocity dispersion. Figure 4 reveals the output pulse width as a function of prism separation. A minimum output pulsewidth of 190 fs was obtained.

The beam quality of the fully amplified output pulse is determined by measuring its transmission through a calibrated pinhole. The focusing optic is a high-quality on-axis parabolic mirror with a 14.8-cm-diameter clear aperture and a focal length of 28.55 $\mathrm{cm}$. At a wavelength of $6.33 \mathrm{~nm}$, this optic produces a diffractionlimited focal spot. With the output beam dimensions of $6.2 \mathrm{~cm}$ by 9 $\mathrm{cm}$, the effective $f$ number for the focusing optic is $\mathrm{f} / 3.7$. In front of the focusing mirror, a beam splitter and a series of partially reflecting mirrors attenuates the pulse in order to eliminate ablation damage of the pinhole. 
Using this configuration, the measured transmission of a circular pinhole $10 \mu \mathrm{m}$ in diameter and carefully centered in the focal plane is $82 \%$. Since the intensity profile of the unfocused beam is fairly flat-topped, w'e assume that the intensity profile in the focal plane is given by the Fraunhofer diffraction integral for a uniformly illuminated rectangular aperture with an aspect ratio of 1.23. With this assumption, the measured transmission of the $10-\mu \mathrm{m}$ pinhole implies FWHM dimensions for the central diffraction spot of $3.4 \times 4.1$ $\mu \mathrm{m}^{2}$. These dimensions are 3.1 times larger than would be obtained for a diffraction-limited beam.

With these focal-spot dimensions, our estimate for the mean intensity obtained with a $250-\mathrm{mJ}, 275$-fs pulse is $6.5 \pm 1.4 \times 10^{18}$ $W / \mathrm{cm}^{2}$. With $\mathrm{f} / 1$ focusing optics, this system will produce an intensity of $8.9 \times 10^{19} \mathrm{~W} / \mathrm{cm}^{2}$, which corresponds to an electric field in the focal volume 39 times the binding field of the hydrogen atom. 


\section{References}

1. S. Watanabe, A. Endoh, M. Watanabe and N. Surakura, Opt. Lett. 13, 580 (1988).

2. S. Szatmari, F. P. Schafer, E. Muller-Horshe and W. Muckenheim, Opt. Commun. 63, 305 (1987).

3. J. R. M. Barr, N. J. Everall, C. J. Hooker, I. N. Ross, M. J. Shaw and W. T. Toner, Opt. Commun. 66, 127 (1988).

4. A. Endoh, M. Watanabe, N. Sarukura and S. Watanabe, Opt. Lett. 14, 353 (1989).

5. T. S. Luk, A. McPherson, G. Gibson, K. Boyer and C. K. Rhodes, Opt. Lett. 14, 1113 (1989).

6. P. Maine, D. Strickland, P. Bado, M. Pessot and G. Mourou, IEEE J. Quantum Electron. QE-24, 398 (1988).

7. A. J. Taylor, J. P. Roberts, T. R. Gosnell and C. S. Lester, Opt. Lett. 14, 444 (1989).

8. A. J. Taylor, C. R. Tallman, J. P. Roberts, C. S. Lester, T. R. Gosnell, P. H. Y. Lee, and G. A. Kyrala, Opt. Lett. 15, 39 (1990)). 
9. Bernhard Dick, Sandor Szatmari, Bela Racz and Fritz Schafer, Opt. Commun. 62, 277 (1987). 


\section{Figure Captions}

1. Schematic diagram of the $\mathrm{XeCl}$ laser system. Measured pulse durations and energies are shown after each stage.

2. Evolution of the pulsewidth through the laser system.

3. Evolution of the pulse spectrum through the laser system.

4. Effect of dispersion compensation by two prism pairs on the output pulsewidth. 


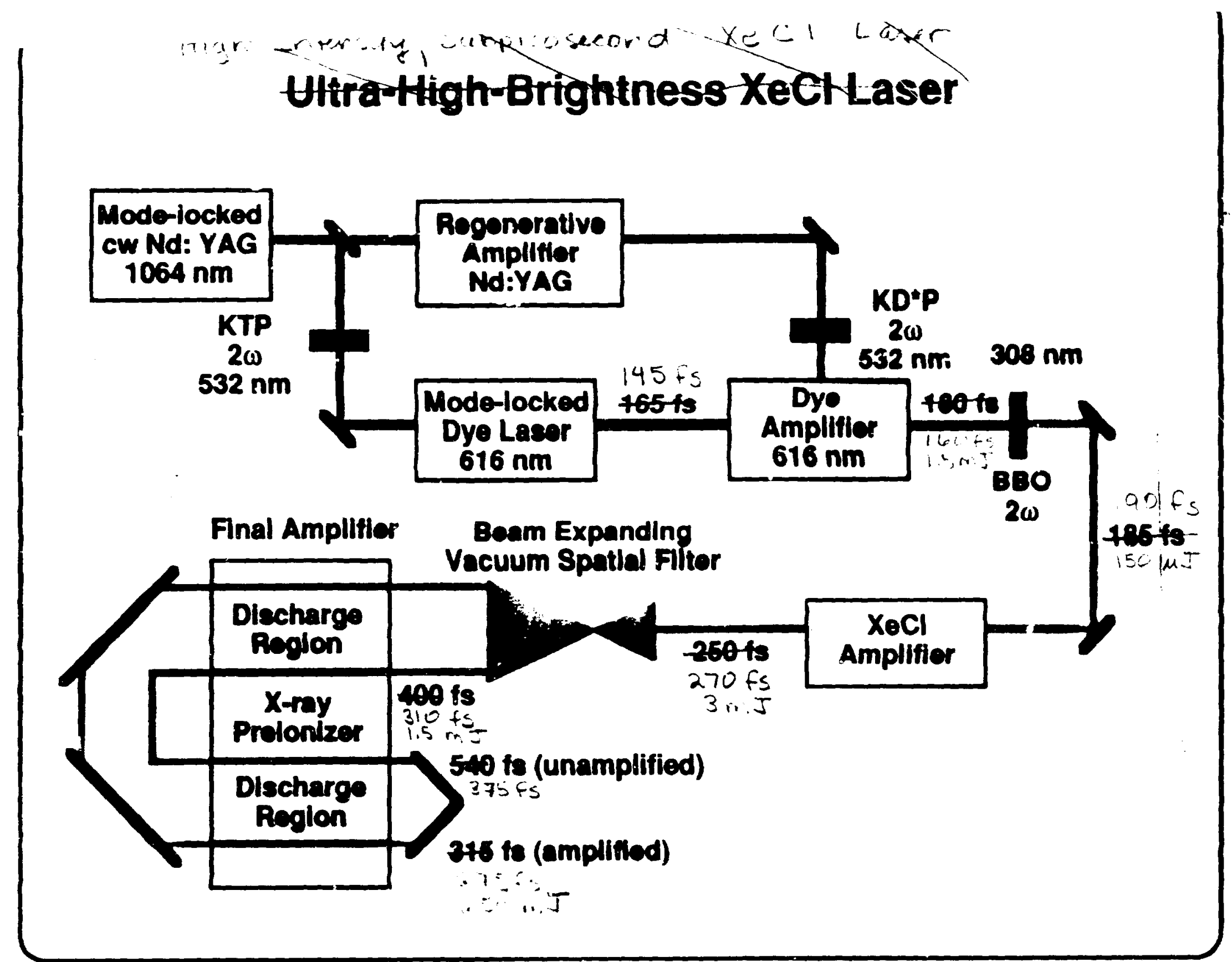

Los Alamos

Figue 1

CLS-80-3068 E 


\section{Evolution Of Pulsewidth Through Laser System}

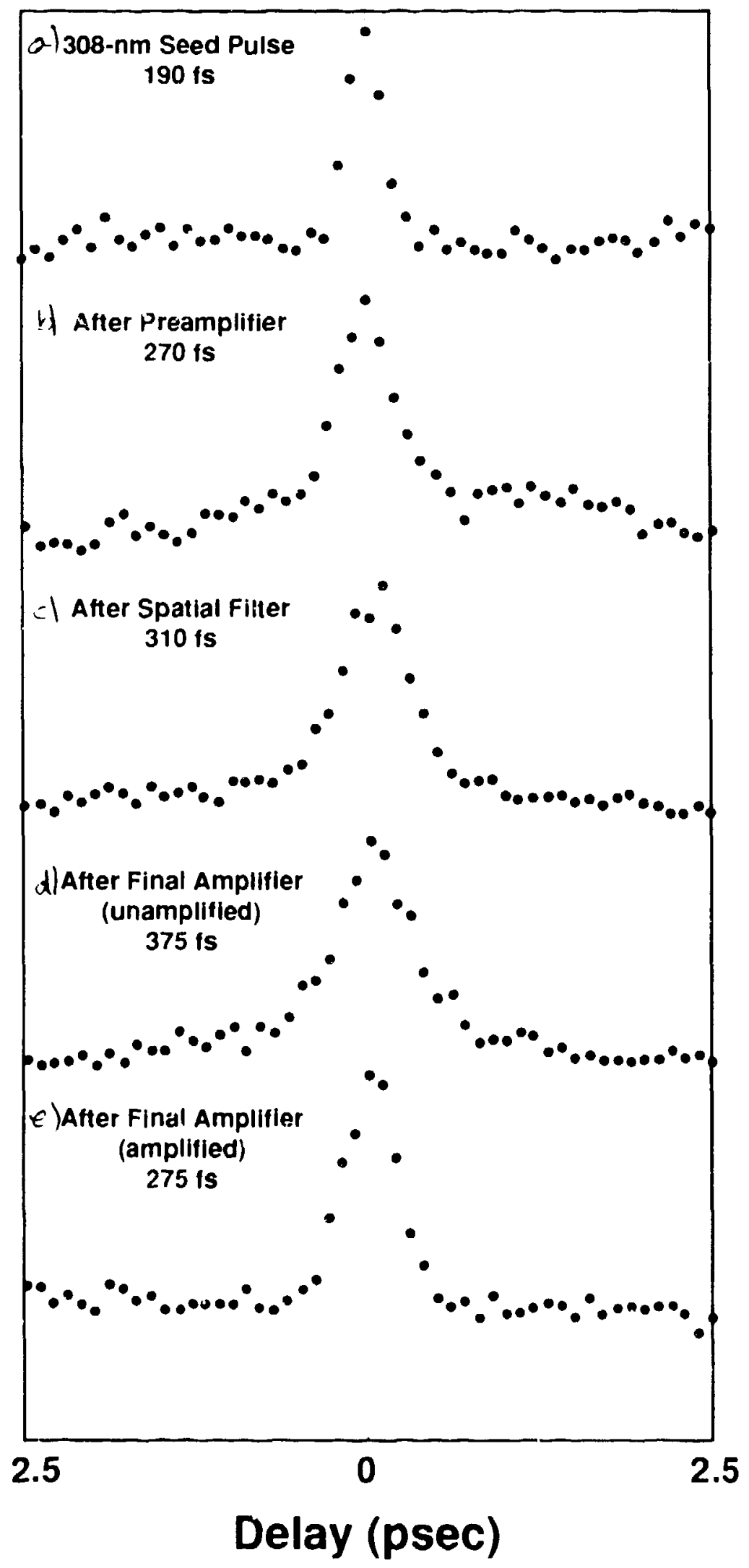

Fignele 

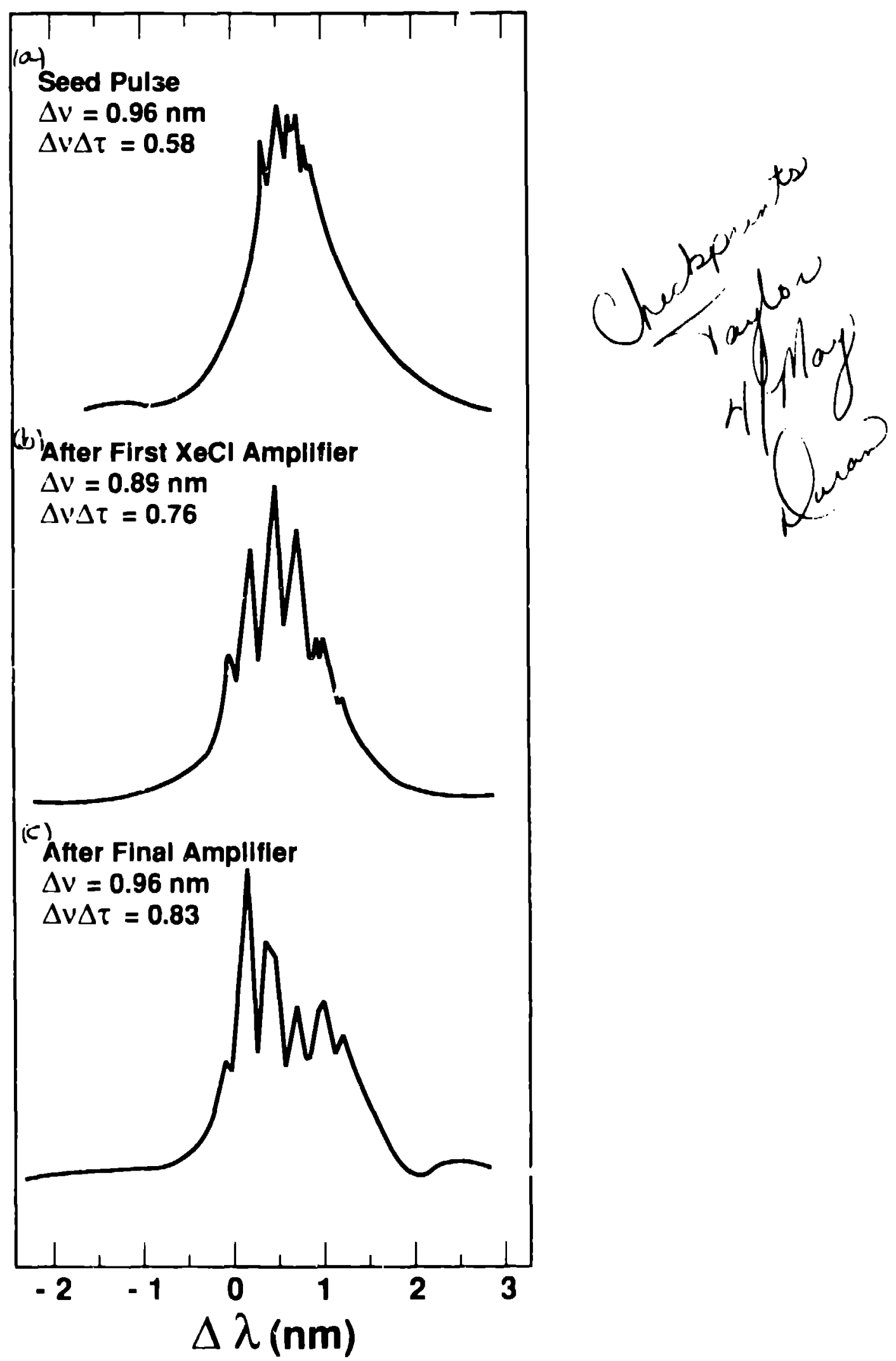

rigues:

10.103 


\section{Effect Of Dispersion Compensation By 4 Prisms On Output Pulsewidth}

(Uncompensated pulsewidth $=\mathbf{4 6 0} \mathrm{fs}$ )

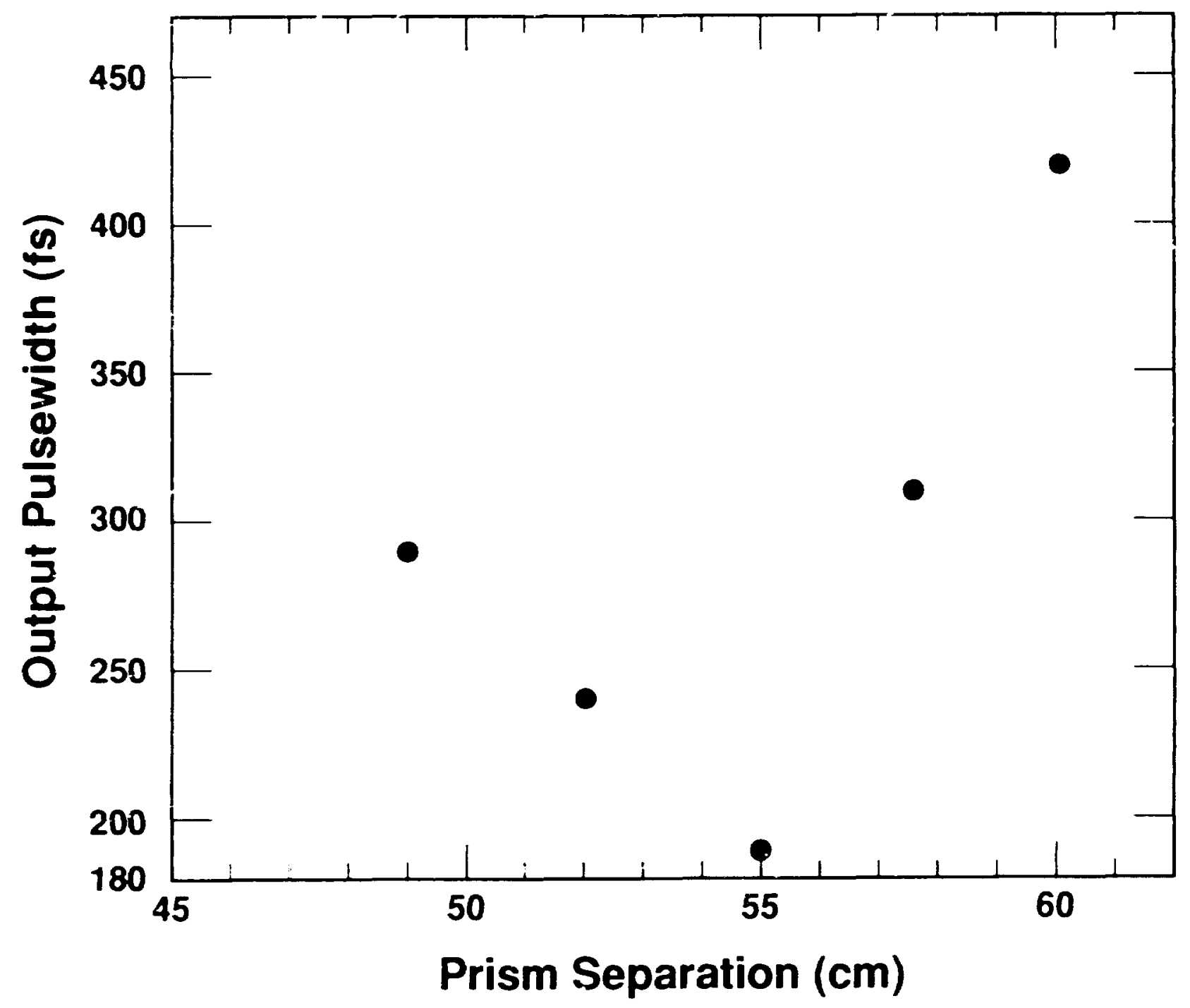

Los Alamos

Figure 4 